\title{
Scientometric Study of The Research Performance on Biodiversity: The Global Perspective
}

\author{
K. Sivasami* \\ Department of Library and Information Science, Annamalai University, Annamalai Nagar - 608 002, Tamilnadu, India.
}

\section{A R T I C LE DE T A I L S}

Article history:

Received 13 May 2021

Accepted 14 June 2021

Available online 12 July 2021

\section{Keywords:}

Scientometric

Biodiversity

Biological Diversity

Ecosystem

\begin{abstract}
A B S T R A C T
This paper examines on scientometric study of the research performance on biodiversity with the data that have been collected from Web of Science database. The study period was chosen from 2011 to 2020 and retrieved 11902 records for the study. This study was planned to find out year-wise publications on biodiversity research from 2011 to 2020 , to examine authorship patterns, to find out the top twenty authors contributions, to find out top twenty institutions that contributed to biodiversity research, to find top twenty sources contributions and to identify top twenty countries contributed on biodiversity research. It was found that the year-wise biodiversity research publications show an increase trend. Among the 17 different document types, in the form of research articles have 9102 papers. Out of the 40843 authors, Schmidt B has occupied the first position with 56 contributed papers. $97.46 \%$ papers were contributed by collaborative authors, and very least number of papers published by single authors'. Totally 178 countries were contributed on biodiversity research publications, amongst India is the fifteenth place with 407 publications.
\end{abstract}

\section{Introduction}

Biological diversity means the variability among living organisms from all sources including inter alia, terrestrial, marine and other aquatic ecosystems and the ecological complexes of which they are a part which includes diversity within species, between species and of ecosystems [1]. It refers to diversity within the biosphere, including genetic, species, and habitat diversity. Biodiversity is a struggle for the just and equitable treatment of others [2,3]. Biological diversity is not homogeneously distributed around the globe [4]. People depend on biodiversity in their daily lives, biodiversity gives rise to health benefits.

Biodiversity encompasses all hereditarily based variation at all levels of organization from genes through populations and species to communities and ecosystems $[5,6]$. Biodiversity provides numerous ecosystem services that are crucial to human well-being at present and in the future. Climate is an integral part of ecosystem functioning and human health is impacted directly and indirectly by results of climatic conditions upon terrestrial and marine ecosystems [7]. Biodiversity underpins the ecological functions and processes that give rise to the benefits provided by ecosystems ("ecosystem services"), including purification of water and air, pest and disease control, pollination, soil fertility, and resilience to climate change. Furthermore, various species and genotypes of organisms provide diverse foods, essential nutrients and medicines [8]. Every year, at least a species goes into extinction while many species of plants and animals face extinction across the world. Biodiversity contributes to human well-being directly through provision of foods, fuels, and fibers, and indirectly through its role in enhancing ecosystem functions that lead to the provision of ecosystem services [9]. Biodiversity loss and ecosystem change can increase the risk of emergence or spread of infectious diseases in animals, plants, humans, including economically important livestock diseases, outbreaks and global pandemics. In recent years, outbreaks of SARS, Ebola, Marburg, Hantavirus, pulmonary, Syndrome, Avian influenza, and malaria have been attributed to human impacts on biodiversity [10]. These scientometric studies help to identify publications on biodiversity research.

The scope of the present study is to find out year wise publications on biodiversity research during 2011-2020, to identify document types wise research publications on biodiversity, to find out top twenty authors contributed on biodiversity research publication, to examine authorship pattern on biodiversity research, to find out top twenty institutions contributed on biodiversity research, to find top twenty sources contributions on biodiversity research publications and to identify top twenty countries contributed on biodiversity research publications.

\section{Experimental Methods}

The data have been accessed from the Web of Science database. The search word has been used 'biodiversity' in the title search box, and the time span field was selected from 2011 to 2020. A total of 11902 records were retrieved, the data downloaded and analyzed using MS Office-Excel as per objectives of the present study.

\subsection{Relative Growth Rate (RGT) and Doubling Time (DT)}

The relative growth rate is the increase in the number of publications/pages per unit of time. Here, one year is taken as the unit of time. The mean relative growth rate $\mathrm{R}(1-2)$ over a specified period of interval can be calculated from the following equation suggested by Mahapatra [11].

$$
\mathrm{R}(1-2)=\frac{\mathrm{W} 2-\mathrm{W} 1}{\mathrm{~T} 2-\mathrm{T} 1}
$$

where, $\mathrm{R}=$ Mean relative growth rate over the specific period of interval; $\mathrm{W} 1=\log \mathrm{w} 1$ (Natural log of initial number of publications/ pages); $\mathrm{W} 2=\log \mathrm{w} 2$ (Natural log of initial number of publications/pages); $\mathrm{T} 2-\mathrm{T} 1=$ Unit difference between the initial time and final time. Therefore,

$\mathrm{R}$ (a) = Relative growth rate per unit of publications per unit of time (year) $\mathrm{R}(\mathrm{p})=$ Relative growth rate per unit of pages per unit of time (year)

\subsection{Doubling Time (DT)}

A direct equivalence exists between the relative growth rate and doubling time. If the number of publications/pages of a subject doubles during a given period, then the difference between the logarithms of the numbers at the beginning and at the end of the period must be the logarithms of the number 2 . This difference has a value of 0.693 . Thus, the corresponding doubling time for publication and pages can be calculated by the following formula:

$$
\text { Doubling time (Dt) -------- }
$$


Doubling time for publications Dt (a) -------

$\mathrm{R}(\mathrm{a})$

\section{Results and Discussion}

Fig. 1 shows that year-wise publications on biodiversity research. Totally 11902 papers were published on biodiversity research from 2011 to 2020 . In the year 2020, 1547 papers has been published as maximum and in the year 2011, 914 articles were published as minimum during the study period. As average nearly 1190 articles were published on biodiversity research and found that there is an increasing trend towards the specified research and reveals that there is an increasing interest among young research buddies towards biodiversity.

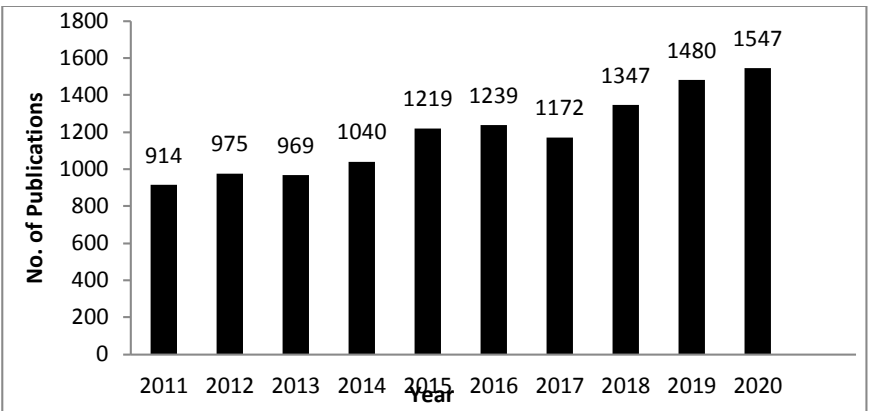

Fig. 1 Year wise publications on biodiversity research

Table 1 Relative growth rate and doubling time of biodiversity research

\begin{tabular}{|c|c|c|c|c|c|c|c|c|c|}
\hline S. No. & Publication Years & Articles & Cumulative & W1 & W2 & W2 - W1(Ra) & Mean (Ra) W2-W1 & Doubling Time & Mean Dt (a) \\
\hline 1 & 2011 & 914 & 914 & & 6.81 & & & & \\
\hline 2 & 2012 & 975 & 1889 & 6.81 & 6.88 & 0.07 & & 9.9 & \\
\hline 3 & 2013 & 969 & 2858 & 6.88 & 6.87 & -0.01 & & -69.3 & \\
\hline 4 & 2014 & 1040 & 3898 & 6.87 & 6.94 & 0.07 & & 9.9 & \\
\hline 5 & 2015 & 1219 & 5117 & 6.94 & 7.1 & 0.16 & 0.07 & 4.3 & -11.3 \\
\hline 6 & 2016 & 1239 & 6356 & 7.1 & 7.12 & 0.02 & & 34.6 & \\
\hline 7 & 2017 & 1172 & 7528 & 7.12 & 7.06 & -0.06 & & -11.5 & \\
\hline 8 & 2018 & 1347 & 8875 & 7.06 & 7.2 & 0.14 & & 4.9 & \\
\hline 9 & 2019 & 1480 & 10355 & 7.2 & 7.33 & 0.13 & & 5.3 & \\
\hline \multirow[t]{2}{*}{10} & 2020 & 1547 & 11902 & 7.33 & 7.34 & 0.01 & 0.08 & 69.3 & 20.5 \\
\hline & Total & 11902 & & & & & 0.07 & & 4.6 \\
\hline
\end{tabular}

Table 1 shows that Relative Growth Rate and Doubling Time of biodiversity research publications, the value of average relative growth rate of publications [R(a)] decreased and increased gradually from 0.07 to 0.01 during 2011 to 2020 and the corresponding mean doubling time [Dt (a)] for the period increasing from -11.3 to 20.5 .

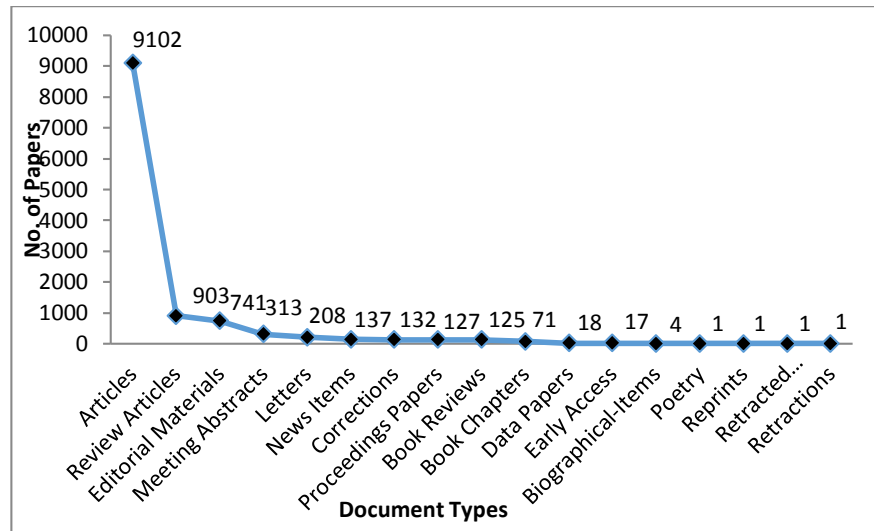

Fig. 2 Document types wise publications on biodiversity research

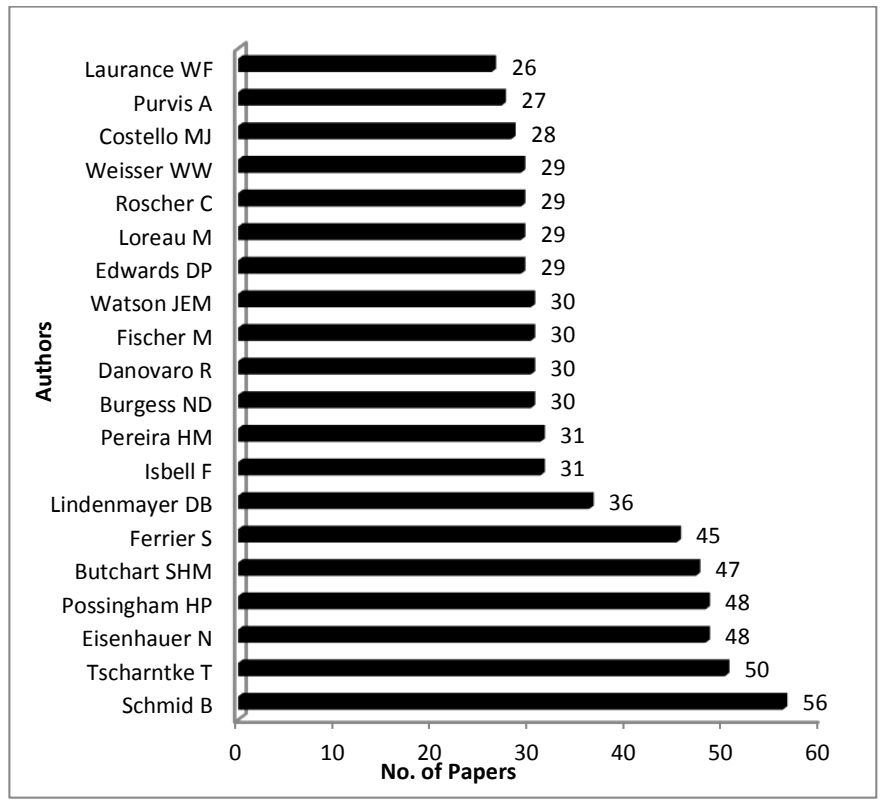

Fig. 3 Top twenty authors contributed on biodiversity research https://doi.org/10.30799/jespr.212.21070201
Fig. 2 shows the document-type wise publications on biodiversity research. Out of 17 document types, 9102 articles have been published as original research, followed by 903 review articles, 741 editorial materials, 313 meeting abstracts, 208 letters, 137 News items, 132 corrections, 127 proceedings papers, 125 book reviews, 71 book chapters and 18 data papers. 17 early access articles, 4 biographical-items and 1 poetry, reprints, retracted publications and retractions have been published.

Fig. 3 shows that the top twenty authors contributed to biodiversity research. A total of 40843 authors were contributed to biodiversity research publications. Among them, the author Schmid B has occupied the first position with 56 contributed papers, Tscharntke T has second place with 50 papers, Eisenhauer $\mathrm{N}$ and Possingham HP has third and fourth place with 48 papers. The author Laurance WF has twentieth place with 26 published articles.

Fig. 4 shows the authorship pattern on biodiversity research publications from 2011 to 2020 . Out of 11902 papers, $40 \%$ articles were contributed by six and above number of authorship pattern, followed by five author's contributions with $26 \%$. Only $3 \%$ articles were contributed by single authors. It was found that many author contribution pattern on biodiversity research publications as $97.46 \%$ by collaborative publications and very least number of publications with single author.

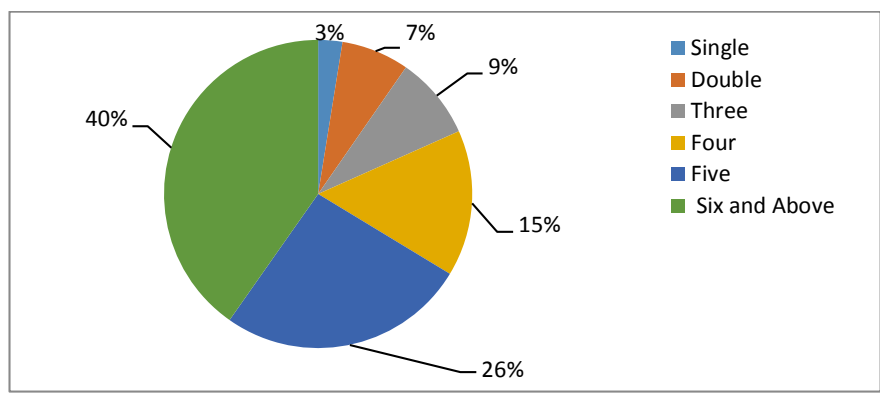

Fig. 4 Authorship pattern on biodiversity research publications

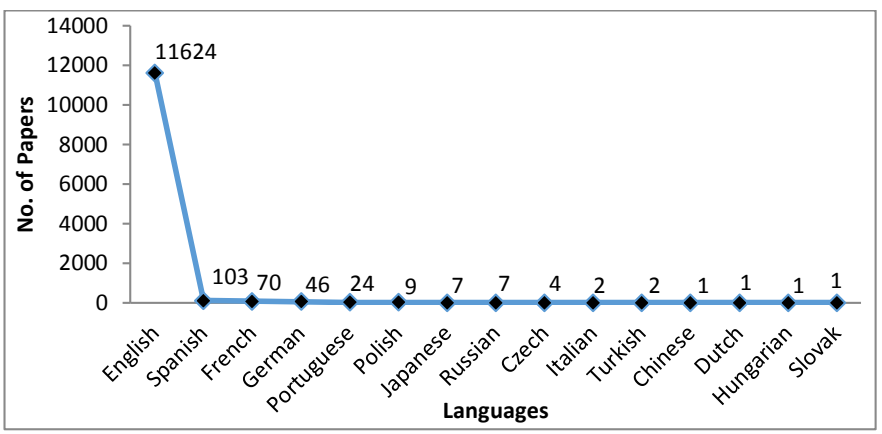

Fig. 5 Language wise research publications on biodiversity 
Table 2 Top twenty institutions contributed on biodiversity research publications

\begin{tabular}{llll}
\hline S. No. & Institutions & Articles & $\%$ \\
\hline 1 & Centre National De La Recherche Scientifique- CNRS & 647 & 5.44 \\
2 & University of California System & 423 & 3.55 \\
3 & Chinese Academy of Sciences & 315 & 2.65 \\
4 & INRAE & 306 & 2.57 \\
5 & Helmholtz Association & 303 & 2.55 \\
6 & Institut De Recherche Pour Le Developpement -IRD & 290 & 2.44 \\
7 & Consejo Superior De Investigaciones Cientificas -CSIC & 289 & 2.43 \\
8 & Commonwealth Scientific Industrial Research & 259 & 2.18 \\
& Organisation - CSIRO & & \\
9 & University of Queensland & 241 & 2.03 \\
10 & CNRS Institute Of Ecology Environment - INEE & 232 & 1.95 \\
11 & Wageningen University Research & 229 & 1.92 \\
12 & Smithsonian Institution & 217 & 1.82 \\
13 & State University System of Florida & 214 & 1.80 \\
14 & Helmholtz Center For Environmental Research -UFZ & 211 & 1.77 \\
15 & Museum National D Histoire Naturelle -MNHN & 209 & 1.76 \\
16 & Swedish University of Agricultural Sciences & 206 & 1.73 \\
17 & Universite De Montpellier & 203 & 1.71 \\
18 & University of Helsinki & 198 & 1.66 \\
19 & University of Cambridge & 194 & 1.63 \\
20 & German Ctr Integrat Biodivers Res Idiv. & 191 & 1.61 \\
\hline & & &
\end{tabular}

Table 3 Top twenty sources contributed on biodiversity research publications

\begin{tabular}{llll}
\hline S. No. & Sources & Articles & $\%$ \\
\hline 1 & Plos-One & 388 & 3.26 \\
2 & Biological Conservation & 320 & 2.69 \\
3 & Biodiversity and Conservation & 287 & 2.41 \\
4 & Ecological Indicators & 203 & 1.71 \\
5 & Journal of Applied Ecology & 134 & 1.13 \\
6 & Science & 130 & 1.09 \\
7 & Scientific Reports & 124 & 1.04 \\
8 & Proceedings of The National Academy of Sciences & 121 & 1.02 \\
& of the United States of America & & \\
9 & Conservation Biology & 119 & 1.00 \\
10 & Conservation Letters & 110 & 0.92 \\
11 & Nature & 105 & 0.88 \\
12 & Sustainability & 99 & 0.83 \\
13 & Forest Ecology and Management & 97 & 0.82 \\
14 & Science of the Total Environment & 97 & 0.82 \\
15 & Diversity and Distributions & 90 & 0.76 \\
16 & Ecology and Evolution & 89 & 0.75 \\
17 & Zootaxa & 89 & 0.75 \\
18 & Agriculture Ecosystems Environment & 88 & 0.74 \\
19 & Trends in Ecology Evolution & 88 & 0.74 \\
20 & Bioscience & 85 & 0.71 \\
\hline
\end{tabular}

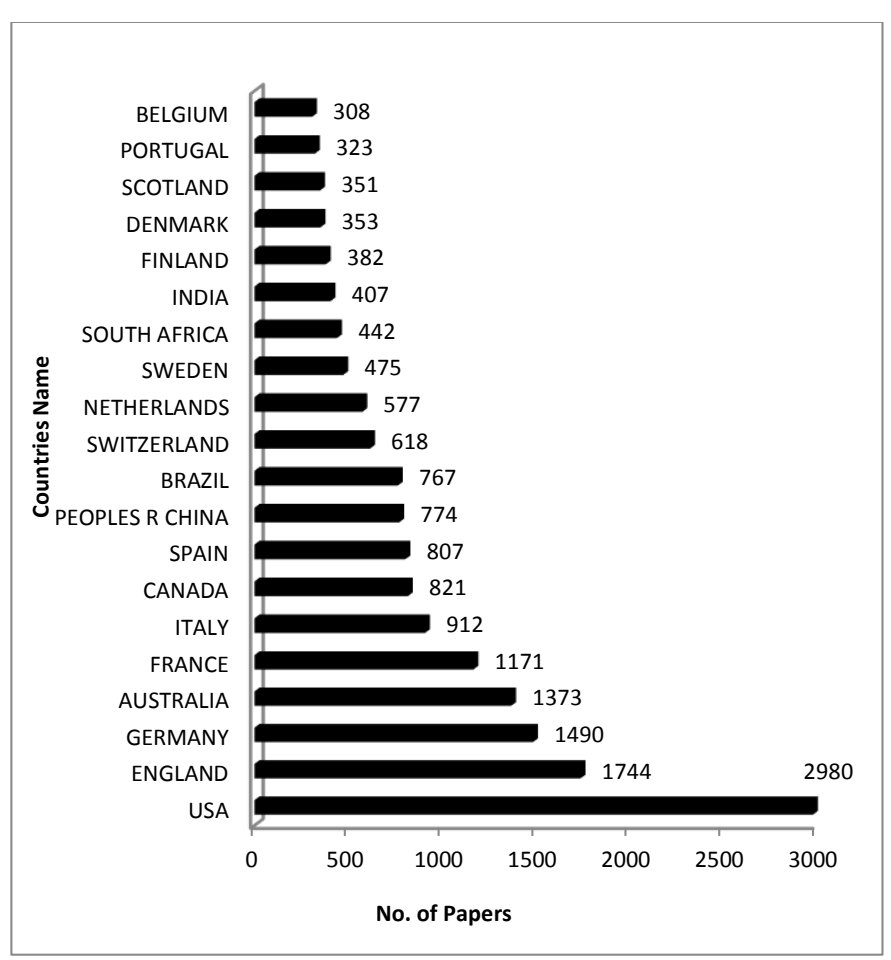

Fig. 6 Top twenty countries contributed on biodiversity research publications https://doi.org/10.30799/jespr.212.21070201
Fig. 5 shows language-wise research publications on biodiversity. Out of 11902 publications 11624 articles has been published in English, followed by 103 articles in Spanish, 70 in French and remaining are as very least count. In the language-wise publications on biodiversity research, English has occupied the first position with $97.66 \%$.

Table 2 shows the top twenty institutions contributed to biodiversity research publications. Totally 8595 institutions were contributed to biodiversity research. Out of them, Centre National De La Recherche Scientifique- CNRS has the first position with $5.44 \%$ articles, the University of California System has second place with $3.55 \%$ and Chinese Academy of Sciences has a third place with $2.65 \%$.

Table 3 shows the top twenty sources contributed to biodiversity research publications. There are 1838 journal sources were contributed to biodiversity research publications. Among them Plos-One occupies first place with 388 papers (3.26\%), Biological Conservation has second place with 320 papers, and the source Biodiversity and Conservation has third place with 287 papers. The journal Bioscience has twentieth place with 85 papers $(0.71 \%)$.

Fig. 6 shows the top twenty countries contributed on biodiversity research. Out of total contributed 178 countries, top twenty counties were listed as shown in Fig. 6. Among the top twenty countries, United States of America occupies first position with 2980 publications, England has second place with 1744 papers and Germany has third place with 1490 publications. India has fifteenth place with 407 publications and Belgium has twentieth place with 308 publications.

\section{Conclusion}

This present study concluding from its data from 2011 to 2020 yearwise publications on biodiversity research, total of 11902 papers were published on biodiversity research with increase trend on year-wise. In the document-type wise publications, there are 17 document types identified in which research articles has the highest count with 9102 articles. From the studied data, it was found that a total of 40843 authors contributed to the biodiversity research publications. Out of them, Schmid B has first position with 56 publications. Authorship pattern reveals $97.46 \%$ papers contributed by collaborative publications and very least number of publications found with single authors. Out of 11902 published data, 11624 articles have been published in English language. Totally 8595 institutions were contributed to biodiversity research and the institution Centre National De La Recherche Scientifique- CNRS has the first position with 647 article contributions. Also, it was found that 1838 publication sources were contributed to biodiversity research publications, among them Plos-One occupies first place with 388 articles. The data reveals that 178 countries were contributed on biodiversity research publications and United States of America occupies first position, England and Germany has second and third position respectively, and India has fifteenth place.

\section{Acknowledgment}

The author thanks the Web of Science for providing publication data.

\section{References}

[1] Anonymous, Convention on Biological Diversity, Secretariat of the Convention on Biological Diversity, Montreal, Canada, 1992.

[2] R.P. Neumann, Biodiversity, Rob Kitchin, Nigel Thrift (Eds.), International Encyclopedia of Human Geography, Elsevier, Netherlands, 2009, pp.308-313.

[3] Kai M.A. Chan, Terre Satterfield, Justice, equity and biodiversity, Simon A. Levin (Ed.), Encyclopedia of Biodiversity, 2nd Edn., Academic Press, United States, 2013, pp.434-441.

[4] José Sarukhán, Rodolfo Dirzo, Biodiversity-rich countries, Simon A. Levin (Ed.), Encyclopedia of Biodiversity, $2^{\text {nd }}$ Edn., Academic Press, United States, 2013, pp.497-508.

[5] A.W. Owen, Biodiversity, R.C. Selley, R.M. Cocks, I.R. Plimer (Eds.), Encyclopedia of Geology, Elsevier, Netherlands, 2005, pp.259-265.

[6] R. Dirzo, E. Mendoza, Biodiversity, Sven Erik Jørgensen, Brian D. Fath (Eds.) Encyclopedia of Ecology, Academic Press, United States, 2008, pp.368-377.

[7] WHO, Biodiversity and Health, World Health Organization, Geneva, 2015 https://www.who.int/news-room/fact-sheets/detail/biodiversity-and-health (Accessed on: 10 $10^{\text {th }}$ May 2021)

[8] WHO, Health, environment and climate change, Human health and biodiversity, Seventy-first world health assembly, World Health Organization, Geneva, 2018.

[9] Seth Binder, Stephen Polasky, Biodiversity, Human Well-Being, and Markets, Simon A Levin (Ed.), Encyclopedia of Biodiversity, 2nd Ed., Academic Press, United States, 2013, pp.435-439.

[10] COHAB, Biodiversity and Global Health, The importance of biodiversity to human Health, COHAB initiative Secretariat, Ireland, 2010.

[11] M. Mahapatra, On the validity of the theory of exponential growth of scientific literature, Proceedings of the $15^{\text {th }}$ IASLIC Conference, Bangalore, India, 1985, pp.61-70. 